\title{
Artificial Cavities and Nest Site Selection by Puerto Rican Parrots: a Multiscale Assessment
}

\section{Cavités artificielles et sélection des sites de nidification par l'Amazone de Porto Rico: une analyse multi-échelle}

\author{
$\underline{\text { Thomas H. White, Jr. }}^{1}$, G. Gordon Brown ${ }^{2}$, and $\underline{\text { Jaime A. Collazo }}^{3}$
}

\begin{abstract}
We examined nest site selection by Puerto Rican Parrots, a secondary cavity nester, at several spatial scales using the nest entrance as the central focal point relative to 20 habitat and spatial variables. The Puerto Rican Parrot is unique in that, since 2001, all known nesting in the wild has occurred in artificial cavities, which also provided us with an opportunity to evaluate nest site selection without confounding effects of the actual nest cavity characteristics. Because of the data limitations imposed by the small population size of this critically endangered endemic species, we employed a distribution-free statistical simulation approach to assess site selection relative to characteristics of used and unused nesting sites. Nest sites selected by Puerto Rican Parrots were characterized by greater horizontal and vertical visibility from the nest entrance, greater density of mature sierra palms, and a more westerly and leeward orientation of nest entrances than unused sites. Our results suggest that nest site selection in this species is an adaptive response to predation pressure, to which the parrots respond by selecting nest sites offering advantages in predator detection and avoidance at all stages of the nesting cycle. We conclude that identifying and replicating the "nest gestalt" of successful nesting sites may facilitate conservation efforts for this and other endangered avian species.
\end{abstract}

RÉSUMÉ. Nous avons examiné la sélection des sites de nidification par l'Amazone de Porto Rico à plusieurs échelles spatiales en utilisant l'entrée du nid comme point de référence. Nous avons quantifié 20 variables spatiales et descripteurs d'habitat. L'Amazone de Porto Rico est un excavateur secondaire. Cette espèce est unique car, depuis 2001, tous les cas de nidification à l'état sauvage ont eu lieu dans des cavités artificielles, ce qui nous a permis d'étudier la sélection des sites de nidification sans les effets confondants des caractéristiques des cavités de nidification individuelles. Puisque les données disponibles sont limitées à cause du faible effectif de la population de cette espèce endémique en voie de disparition, nous avons employé une approche de simulation de Monte Carlo afin d'évaluer la sélection des sites relativement aux caractéristiques des sites de nidification utilisés et inutilisés. Par rapport aux sites inutilisés, les sites de nidification sélectionnés par l'Amazone de Porto Rico étaient caractérisés par une plus grande visibilité horizontale et verticale à partir de l'entrée du nid, une plus grande densité de palmiers sierra matures et une orientation des entrées des nids plus à l'ouest et exposée au vent. Nos résultats suggèrent que la sélection des sites de nidification constitue une réponse adaptive à la pression de prédation: les sites choisis offrent une meilleure détection des prédateurs à tous les stades du cycle de nidification. Nous concluons que l'identification et la réplication de la « gestalt » des sites de nidification à succès peuvent faciliter les efforts de conservation de cette espèce et d'autres espèces d'oiseaux en péril.

Key Words: Amazona vittata; artificial cavities; nest site; predation; Puerto Rican Parrot; selection; simulation method; visibility

${ }^{1}$ U.S. Fish and Wildlife Service - Puerto Rican Parrot Recovery Program, ${ }^{2}$ RTI International, ${ }^{3}$ U.S. Geological Survey, B.R.D., North Carolina State University

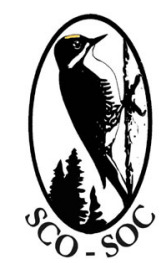

Sponsored by the Society of Canadian Ornithologists and Bird Studies Canada Parrainée par la Société des ornithologistes du Canada et Études d'oiseaux Canada

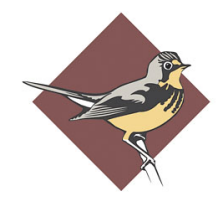

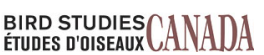




\section{INTRODUCTION}

Resource selection by an animal can be regarded as hierarchical or ordered (Johnson 1980), with geographic range, home range, feeding areas, and food items each constituting different orders of selection. Within this hierarchy, however, the selection of an appropriate natal site (i.e., den, nest) is arguably one of the most profound choices affecting an individual's fitness, and ultimately, a species' persistence (Walsberg 1981, Li and Martin 1991, Carey et al. 1997, White et al. 2001). For any given species, natal site selection is especially important because failed reproductive efforts may retard population growth (Ricklefs 1969, Caughley 1977). For endangered species or geographically isolated populations, reproductive failures may also increase the probability of extinction (Loiselle and Hoppes 1983, Sieving 1992).

Biologists frequently attempt to assess resource selection at one or more orders. With avian species, this assessment frequently addresses nest site selection (e.g., Stauffer and Best 1982, Sedgwick and Knopf 1990, Li and Martin 1991, Filliater et al. 1994, Roper 2003). Although most studies of nest site selection have typically examined selection at the spatial level of the nest site or nest itself (e.g., Joern and Jackson 1983, Munro and Rounds 1985, Holway 1991, Götmark et al. 1995), increasing numbers of studies have examined avian habitat and nest site selection at multiple spatial scales (e.g., Gutzwiler and Anderson 1987, Esely and Bollinger 2001, Hardy and Morrison 2001), or using multiple statistical methods (e.g., MacKenzie et al. 1982, Sedgwick and Knopf 1990, Battin and Lawler 2006). Understanding nest site selection at multiple spatial scales can provide insights into how specific environmental components may interact to ultimately influence reproductive outcome (Nilsson 1984, Li and Martin 1991, Doligez et al. 1999, Weidinger 2002). Such knowledge can be invaluable in the case of intensively managed wild populations, such as those of game species and endangered species.

An example of an intensively managed wild population is the critically endangered endemic Puerto Rican Parrot (Amazona vittata), one of the ten most endangered birds in the world (Wiley et al. 2004). Once abundant throughout Puerto Rico, this species has been restricted to less than 20000 ha of subtropical montane rainforest in northeastern Puerto Rico for over 60 years (Snyder et al. 1987,
Wiley et al. 2004). Research on the nesting ecology of the remnant wild population began in the 1950s (Rodriguez-Vidal 1959). In 1967, the species was listed as endangered, and active recovery efforts began in 1968 (Snyder et al. 1987). Intensive nest management to improve reproductive success began in 1973 and continues to date (Wiley et al. 2004). During this time, management actions have included repairing damaged natural nest cavities, enhancing existing natural cavities, and deploying various types of artificial cavities (Snyder et al. 1987, Vilella and Garcia 1995, U.S. Fish and Wildlife Service 1999). However, despite all management efforts, the known number of active wild nests has never exceeded six in any year since recovery efforts began (White et al. 2005a).

A key component of recent management efforts for the Puerto Rican Parrot has been the provisioning of artificial nest cavities to augment the paucity of suitable natural cavities in the nesting areas (Snyder et al. 1987, White et al. 2005a). Artificial nests, combined with intensive monitoring of nesting activities (Lindsey 1992, White and Vilella 2004) have been instrumental in improving individual nest success (Wiley et al. 2004). Regardless of whether the nest is natural or artificial, nest site fidelity is high, and active nests are normally used for several years (Snyder et al. 1987, White et al. 2005a). A likely contributor to the observed fidelity is success of previous reproductive attempts (Switzer 1997, Doligez et al. 1999). A recurrent feature of nest site fidelity in Puerto Rican Parrots is that it is directed to specific nest sites within a breeding area. Over time, different nesting pairs tend to use the same sites rather than pioneer new ones. Moreover, nest sites are also reused following substantial modifications to the cavities themselves, suggesting selection for factors extrinsic to the actual cavities. This situation begs the question: why do these birds consistently use particular nest sites and not others?

Because all known nesting activity by wild Puerto Rican Parrots has, since 2001, occurred in artificial nest cavities (White et al. 2005a), we were provided with an opportunity to examine habitat and spatial characteristics at all known nest sites, without the confounding effects of differences intrinsic to the cavities per se (see Belles-Isles and Picman 1986, Lumsden 1986, Finch 1989). To this end, our objective was to answer the following questions: 1) Are there detectable differences between used and unused nest sites? 2) Can habitat and spatial characteristics be used to differentiate and thus 
predict used vs. unused sites? Correctly identifying biologically meaningful variables that influence nest site selection may provide greater understanding of how management actions may affect reproductive success (Martin 1992, Steele 1993, Schmidt and Whelan 1999). We also discuss the management implications of our findings for the continuing recovery efforts for this and other endangered avian species.

\section{STUDY AREA}

We conducted this study in the Caribbean National Forest (CNF), also known as the Luquillo Experimental Forest, located in the Luquillo Mountains of northeastern Puerto Rico (18 $18^{\circ} \mathrm{N}$, $\left.65^{\circ} 47^{\prime} \mathrm{W}\right)$. The CNF comprises 19650 ha of subtropical rainforest, with elevations ranging from 200-1074 m above sea level, and contains four dominant forest types: namely, the tabonuco (Dacryodes excelsa) zone at elevations to $600 \mathrm{~m}$, the palo colorado (Cyrilla racemiflora) zone above $600 \mathrm{~m}$, sierra palm (Prestoea montana) stands on steep slopes and ravines throughout the CNF, and dwarf cloud forest on the highest peaks and ridges (Snyder et al. 1987). Puerto Rican Parrot nests, however, are found mainly at elevations from 500$700 \mathrm{~m}$ at the transition between the tabonuco and palo colorado forest types, with palo colorado being the primary species used for nesting (Snyder et al. 1987, White and Vilella 2004). Other principal overstorey species in the parrot nesting area include Micropholis garcinaefolia, M. chrysophylloides, Magnolia splendens, Clusia grisebachiana, Cecropia peltata, Ocotea spathulata, Manilkara bidentata, Calycogonium squamulosum, and Sloanea berteriana (Snyder et al. 1987). Precipitation is copious, ranging annually from 200 $\mathrm{cm}$ at lower elevations to $>500 \mathrm{~cm}$ at the highest peaks. Annual temperatures range from $11^{\circ}$ to $32^{\circ}$ $\mathrm{C}$, averaging $21^{\circ} \mathrm{C}$ (Lindsey et al. 1991).

\section{METHODS}

\section{Data Collection}

We grouped all available artificial nest cavities ( $n$ $=19$ ) into two groups: namely, those that had been used at least once within the past 6 years (20012006; $n=7)$, and those that had not been used in any previous year $(n=12)$. We standardized the artificial nest cavity design beginning in 2001 through 2002 (White et al. 2005a); one older artificial cavity used by parrots in 2001 was changed to the standardized design in 2002 and parrot use of the site continued. We classified a nest as "used" if egg laying had been initiated. Data were collected at all nest sites during July-August 2005, immediately following the annual nesting season (February-June). At each site, we measured 20 variables in two general categories: 1) nest entrance characteristics, and 2) nest site characteristics. Two additional variables, nest tree species and whether the nest tree was canopy emergent or not, also were recorded but not used in later analyses as they were invariant (i.e., all artificial nests were in canopyemergent palo colorado trees). We focused particular attention on spatial characteristics relative to the nest entrance because final decisions by Puerto Rican Parrots regarding acceptance of a nest site likely occur at, or near, the nest entrance (Snyder et al. 1987, Lindsey 1992, Wilson et al. 1995, White and Vilella 2004). Also, with standardized artificial cavities, the nest entrance constitutes the primary spatial nexus between a homogeneous internal environment and the heterogeneous external environment. Further, we examined variables at five spatial scales: 1) spatial characteristics of the nest entrance itself (e.g., height above ground, aspect, etc.), 2) selected habitat characteristics within $15 \mathrm{~m}$ of the nest site, 3) selected habitat characteristics within $30 \mathrm{~m}$ of the nest site, 4) selected habitat characteristics within $100 \mathrm{~m}$ of the nest site, and 5) spatial relationships between all nest sites within the entire parrot nesting area.

We determined nest entrance height above ground, distance below surrounding canopy, nest tree height, and ground slope at nest site using a clinometer. Nest entrance aspect and aspect relative to site slope were determined using a compass. Aspect relative to site slope was the absolute $(+/-)$ degree of angular deviation of the nest entrance from straight downhill $\left(0^{\circ}\right)$ to straight uphill $\left(180^{\circ}\right)$, and was placed into two categories corresponding to $90^{\circ}$ increments (i.e., downhill, uphill) of angular deviation. We used a spherical densiometer to determine canopy cover at nest sites. At each site, we used the mean of four densiometer readings oriented along each of four cardinal compass directions. We defined horizontal visibility as the horizontal distance from the nest entrance to the nearest point of visual obstruction by surrounding vegetation in each of eight compass directions (i.e., $45^{\circ}$ increments). We then used these distances to 
calculate the total area of the horizontal field of view from the nest entrance. We further divided horizontal visibility into two hemispheres (frontal and rear) to evaluate differences in visibility within these regions. Distance from nest entrance to nearest branch, both horizontally and vertically, was also recorded. A point-center quarter method was used to determine distance and bearing to the nearest canopy tree in each of four quadrants (Finch 1989). We defined a canopy tree as any tree whose crown made up part of the surrounding canopy. We then used these measurements to calculate the area of a polygon representing degree of "openness" around the nest tree relative to spacing of nearest canopy trees. Visibility and openness at nest sites were examined because several studies have suggested that, for some species, use of more open nesting sites is an adaptive response to predation (Belles-Isles and Picman 1986, Finch 1989, Götmark et al. 1995, Koenig et al. 2007; but see Joern and Jackson 1983, Holway 1991, Martin 1993, Weidinger 2002), and because Red-tailed Hawks (Buteo jamaicensis) are a major predator of Puerto Rican Parrots (Snyder et al. 1987, White et al. 2005b). Distance to nearest snag (i.e., dead standing tree) also was recorded, because snags are frequently used as hunting perches by Red-tailed Hawks in the CNF (Snyder et al. 1987, Nimitz 2005). Except for nest and tree heights, we obtained distance measures using a 30.5 $\mathrm{m}$ steel tape. We used a nested circular plot (using nest tree as center) to determine number of woody stems with a diameter at breast height $(\mathrm{dbh})>10 \mathrm{~cm}$ within $15 \mathrm{~m}$ of the nest site, number of mature (i.e., flowering, fruiting, senescent) sierra palms within $30 \mathrm{~m}$, and number of canopy-emergent trees within $100 \mathrm{~m}$ of the nest site. We enumerated sierra palms because they provide the primary source of food for Puerto Rican Parrots during the nesting season (Snyder et al. 1987, Wunderle 1999). Finally, we used a geographic positioning system (GPS) to obtain elevation and coordinates of each nest site, and to determine distance to nearest active nest site. Because not all used nests were active in all years, we determined distance to nearest active nest each year at time " $t$ " and "t-1" (except for year 2001) to account for any autocorrelation that could influence probability of a nest site being used in a given year due to proximity of an active nest the previous year (Switzer 1997, Doligez et al. 1999, Brown et al. 2000). Although presence and number of attached vines and lianas on nest trees have also been included in some nesting studies (e.g., Roper 2003, Koenig et al. 2007), most such vines become detached and are routinely removed from nest trees during the installation and maintenance of artificial nests for Puerto Rican Parrots. Also, an horizontally oriented "entrance vine" is affixed to the entrance of all artificial nests to facilitate access by parrots (Vilella and Garcia 1995, White et al. 2005a), further precluding meaningful comparisons between used and unused sites for this characteristic.

\section{Data Analyses}

The number of nest sites varied from year to year. During the study there were as many as 19 available sites in a given year, seven of which were selected at least once. However, examination of the data suggested that site selection from year to year was not independent; specifically, site selection in a given year appeared to be conditional on site use during the previous year. We assumed that site selection was only a function of the previous year (i.e., Markov process). We chose nest site to be the experimental unit; yearly site selections were then considered repeated measures within a unit. No consideration was given to the specific pair of birds that were nesting.

\section{Correlation of Yearly Site Selection}

The correlation from year to year was determined empirically from the data. To determine this correlation we examined the site selection pattern for 2002-2006. The study began in 2001; therefore, there was no potential for correlation with the previous year. This implied that there were 24 site selections during years 2002-2006. Twenty-one of these 24 possible site selections resulted in the use of a nest site that was used the previous year, yielding a conditional annual probability of site reuse of $0.875(21 / 24)$. Under the assumption of random site selection, the re-use probability would be 0.324 (24/74), given 74 potential site selections during the study and 24 actual selections. We tested this assumption with a z-test (Agresti 1990) and found it invalid $(\mathrm{z}=10.23, P<0.001)$.

Because of the data characteristics, standard assumptions such as normality, homogeneity, and independence were invalid. The exceptions were the variables distance to nearest active nest at time " $t$ " and time "t-1," which also varied from year to year at any given site depending on actual patterns of site use; all other site variables were considered constant 
during the study. We used two-sample $t$-tests (Sokal and Rohlf 1981) to evaluate differences in distances to nearest active nests. For all other variables, we conducted exact tests (Sokal and Rohlf 1981) based on the distribution of a given test statistic. First, we proposed a meaningful measure of the data (test statistic) and calculated its value using the actual data. Second, we used a computer algorithm to simulate multiple replicate data sets. Third, we calculated the proposed test statistic for each of the replicate data sets. Finally, we determined the $P$ value for the actual test statistic based on the distribution of test statistics from the replicate data sets. This type of simulation approach accounted for all of the characteristics of the data and the design of the study without having to make unwarranted assumptions about any given test statistic.

\section{Simulation Method}

We used a Monte Carlo simulation method (Chernick 1999) to calculate univariate tests of significance to detect relationships between site selection and nest site variables. The method involved simulating parrot site selection preference under the assumption that all sites were equally desirable for nesting. The simulation was started by randomly assigning the five nesting pairs to the available nest sites in 2001. The selection of nest sites in 2002 was conditional on which sites were selected in 2001. If a given site was selected in 2001, then the probability that it would be selected in 2002 was 0.875 . The first step was to determine how many sites were re-selected, then determine how many new sites would need to be selected. If new site selection was required, the new sites for 2002 were then randomly determined from the available sites that were not selected in 2001 . The end result is that five sites would be used in 2002. This process was repeated for all years. For 2005-2006 the number of nesting pairs dropped from five to four. To simulate this occurrence, one nest site that was used in 2005 was randomly dropped for 2006. The remaining four sites then used the same simulation process as described above.

The test statistic used was the sum of the values for any given nest site covariate for all 29 selected sites. First, this sum was first calculated for the actual data. Next, the sum was then determined for each of 10000 replicate data sets. In this manner, an empirical distribution of the test statistic was created. The $P$ value for the actual test statistic was determined by calculating the proportion of observations from the simulation that were more extreme than the sum from the actual data. Because this is an exact test, there are no degrees of freedom. Because of the small sample sizes and associated reduced statistical power, we considered differences significant at $P \leq 0.10$ to reduce Type II error (Sokal and Rohlf 1981). We report all means with their $90 \%$ confidence interval.

\section{RESULTS}

Habitat and spatial data (Table 1) were obtained at 19 nest sites, of which seven were classified as "used" and 12 as "unused" sites. Site elevation was not a factor in site selection $(P=0.84)$, nor was distance to nearest active nest at time " $\mathrm{t}$ " $(t=0.19$, $\mathrm{df}=31, P=0.85)$ or "t-1" $(t=0.23, \mathrm{df}=29, P=$ $0.82)$. There was no difference in height of nest tree $(P=0.94)$, diameter of nest tree $(P=0.18)$, height of nest entrance above ground $(P=0.82)$, or distance below canopy $(P=0.38)$ between selected and nonselected nest sites. Site selection also was not a function of distance from nest entrance to nearest horizontal $(P=0.32)$ or vertical $(P=0.95)$ branch, or distance to nearest snag $(P=0.96)$. However, nest entrance aspect was a factor in site selection with the East/West aspect being predictive $(P=0.04)$, whereas the North/South aspect lacked preference $(P=0.64)$. Nest entrances at selected sites were oriented primarily $(5 / 7)$ in a westerly direction, with those at unused sites oriented primarily $(8 / 12)$ in an easterly direction. Ground slope was not a predictor of site selection $(P=0.62)$, although nest entrance aspect relative to site slope was marginally significant $(P=0.10)$ at used and unused nest sites. Nest entrances at selected sites mainly (6/7) faced downhill, whereas nest entrances at other sites tended (7/12) to face uphill. Canopy cover also was a factor $(P=0.01)$ in site selection, as was horizontal visibility in the rear hemisphere $(P=0.01)$. However, horizontal visibility in the frontal hemisphere did not differ $(P=0.30)$ between used and unused nest sites. Openness relative to adjacent canopy trees also was predictive $(P=0.08)$ of site selection. Overall, used nest sites were characterized by greater outward visibility from the nest entrance, both horizontally and vertically, than unused sites. There was no difference $(P=0.93)$ in the number of woody stems $(>10 \mathrm{~cm} \mathrm{dbh})$ present within $15 \mathrm{~m}$, although the number of mature sierra palms was greater $(P=0.04)$ at selected sites than at other sites. Nearly twice as many mature palms 
were found near used nests as unused nests (Table 1). Finally, nest site selection did not appear to be a function of the number of canopy-emergent trees within $100 \mathrm{~m}(P=0.77)$.

\section{DISCUSSION}

Our goal was to predict site selection based on characteristics of the nesting sites available to a very small breeding population. To do so, we used nontraditional statistical techniques to obtain meaningful inferences because of inherent sample size limitations, finite nature of the selection process, and temporal correlation evident in site selection. Our exact test has several appealing properties. First, it does not depend on any distributional assumptions (normality, homogeneity, etc). Second, the temporal correlation in site selection is implicitly accounted for. Third, the experimental design is implicitly controlled for. Finch (1989) argued that, if nest sites are scarce, nesting preferences might be difficult to detect because of use of suboptimal sites by some individuals. In our case, the number of available unused nest sites exceeded both the number of used sites and the number of wild nesting pairs. Moreover, artificial nest cavities were abundant, occurring throughout the known nesting area (approx. 30 ha) at a density of approximately 1 per 1.6 ha. Thus, we believe that nests used represented those nests actually selected by nesting pairs. Further, we used a predictive model that considered the number of times each nest was used in "weighting" the differences in relevant habitat characteristics. This approach is effective in discerning site selection because it uses the nest site as the experimental unit, rather than the nesting pair (Finch 1989).

We considered the possibility that the cumulative history of nest management for the Puerto Rican Parrot may have influenced current patterns of nest site selection. Over time, parrots have successfully used natural cavities, modified natural cavities, and various types of artificial structures (Snyder et al. 1987, Vilella and Garcia 1995, White et al. 2005a). Despite the continual evolution of nest management, however, parrots have consistently demonstrated fidelity to traditional nesting areas and sites. In this study, most (5/7) used artificial cavities occurred at sites in which they replaced a previously existing used natural cavity. All other artificial cavities, including two cavities used in this study, occurred at sites without a previously used natural cavity, although within the traditional nesting area at sites characterized by frequent presence of parrots and qualitatively similar attributes (e.g., habitat type, tree species) as historically used sites (White et al. 2005a). The fact that successive nesting pairs continue to use such sites strongly suggests that site selection, rather than management actions, is responsible for observed patterns. Over time, the net effect of nest management has been an increase in nest success (Snyder et al. 1987, Wiley et al. 2004), yet actual parrot nesting traditions and behavior have apparently remained constant (Wilson et al. 1995, 1997, U.S. Fish and Wildlife Service 1999). Indeed, it seems that parrot nesting behavior has had more influence on management actions than vice versa (U.S. Fish and Wildlife Service 1999, Wiley et al. 2004). Given the current population trajectory for the Puerto Rican Parrot (Wiley et al. 2004, Collazo et al. 2006), this species is likely to be subject to continued intensive nest management for the foreseeable future. Accordingly, we believe our inferences are valid for the population in question.

Used and unused nest sites of Puerto Rican Parrots differed in several aspects (Table 1). Nests used by Puerto Rican Parrots occurred in more open sites, relative to horizontal and vertical visibility from the nest entrance, than unused nests. Entrances of used nests also tended to face in a westerly and downhill direction. Further, used nest sites were typified by a greater abundance of mature sierra palms than unused sites. In contrast, greater visual obstruction from the nest entrance, uphill and eastward oriented nest entrances, and fewer mature sierra palms characterized unused nest sites.

Rodriguez-Vidal (1959) and Snyder et al. (1987) reported that most natural nest cavities used by Puerto Rican Parrots also faced in a downhill and generally westward direction, and attributed this to greater frequency of such cavities in palo colorado trees, the predominant species used for nesting by Puerto Rican Parrots. The nonrandom occurrence of such cavities was further attributed to inclination angles of palo colorado trees on slopes in the CNF, resulting in higher incidence of limb breakage and thus cavity formation on the lower (i.e., downhill) sides (Snyder et al. 1987). However, orientations of artificial cavities in this study were not dependent on such factors and were, in fact, random when considered as a group. Also, we found no difference 
Table 1. Summary statistics of 20 habitat and spatial characteristics of all used and unused Puerto Rican Parrot nest sites in the Caribbean National Forest, Puerto Rico, 2001-2006. Total sample size was seven for used sites and 12 for unused sites.

\begin{tabular}{|c|c|c|c|c|c|}
\hline \multirow[t]{2}{*}{ Site characteristic } & \multicolumn{2}{|c|}{ Used nest sites } & \multicolumn{2}{|c|}{ Unused nest sites } & \multirow[t]{2}{*}{ Difference } \\
\hline & Mean & $\mathrm{CI}^{\mathrm{a}}$ & Mean & $\mathrm{CI}$ & \\
\hline Site elevation (m) & 613 & $590-636$ & 620 & $611-629$ & $\mathrm{n} / \mathrm{s}^{\mathrm{b}}$ \\
\hline Distance at time $t^{\mathrm{c}}$ & 274 & 199-349 & 266 & $232-300$ & $\mathrm{n} / \mathrm{s}$ \\
\hline Distance at time $t-1^{\mathrm{c}}$ & 270 & $195-345$ & 274 & $231-317$ & $\mathrm{n} / \mathrm{s}$ \\
\hline Nest entrance height ${ }^{\mathrm{d}}(\mathrm{m})$ & 10.8 & $9.2-12.4$ & 9.1 & $8.1-10.1$ & $\mathrm{n} / \mathrm{s}$ \\
\hline Nest tree height (m) & 19.7 & $17.6-21.8$ & 18.0 & $16.1-19.9$ & $\mathrm{n} / \mathrm{s}$ \\
\hline Distance to canopy ${ }^{\mathrm{e}}$ & 7.0 & $5.4-8.6$ & 7.9 & $6.4-9.4$ & $\mathrm{n} / \mathrm{s}$ \\
\hline Nearest branch $^{\mathrm{e}}$ (horizontal) & 1.2 & $0.9-1.5$ & 1.5 & $1.0-2.0$ & $\mathrm{n} / \mathrm{s}$ \\
\hline Nearest branch ${ }^{\mathrm{e}}$ (vertical) & 1.9 & $1.1-2.7$ & 1.9 & $1.2-2.6$ & $\mathrm{n} / \mathrm{s}$ \\
\hline Nearest snag ${ }^{\mathrm{e}}(\mathrm{m})$ & 15.9 & $7.4-24.4$ & 22.6 & $7.0-38.2$ & $\mathrm{n} / \mathrm{s}$ \\
\hline Nest tree $\mathrm{dbh}^{\mathrm{f}}(\mathrm{cm})$ & 104.6 & $88.4-120.8$ & 78.2 & $64.9-91.5$ & $\mathrm{n} / \mathrm{s}$ \\
\hline Nest entrance aspect ${ }^{\text {aa }}$ & $262^{\circ}$ & $\mathrm{n} / \mathrm{a}^{\mathrm{bb}}$ & $101^{\circ}$ & $\mathrm{n} / \mathrm{a}$ & $P=0.04$ \\
\hline Nest site slope (\%) & 26 & $18.6-33.4$ & 28 & $17.3-38.7$ & $\mathrm{n} / \mathrm{s}$ \\
\hline Canopy cover (\%) & 82 & $78.1-85.9$ & 89 & $86.7-91.3$ & $P=0.01$ \\
\hline Frontal visibility $\left(\mathrm{m}^{2}\right)$ & 303.0 & $216.6-389.4$ & 117.6 & $69.6-165.6$ & $\mathrm{n} / \mathrm{s}$ \\
\hline Rear visibility $\left(\mathrm{m}^{2}\right)$ & 178.6 & $128.9-228.3$ & 71.9 & $51.4-92.4$ & $P=0.01$ \\
\hline Site openness $\left(\mathrm{m}^{2}\right)$ & 97.8 & $62.4-133.2$ & 59.5 & $46.4-72.6$ & $P=0.08$ \\
\hline Woody stems ${ }^{c c}$ & 84.1 & $75.3-92.9$ & 80.1 & $70.6-89.6$ & $\mathrm{n} / \mathrm{s}$ \\
\hline Mature sierra palms ${ }^{\mathrm{dd}}$ & 69.7 & $55.3-84.1$ & 37.1 & $23.1-51.2$ & $P=0.04$ \\
\hline Canopy emergents ${ }^{\mathrm{ee}}$ & 11.3 & $10.0-12.6$ & 11.0 & $9.7-12.3$ & $\mathrm{n} / \mathrm{s}$ \\
\hline Downhill-facing nest entrances & $6 / 7$ & $\mathrm{n} / \mathrm{a}$ & $5 / 12$ & $\mathrm{n} / \mathrm{a}$ & $P=0.10$ \\
\hline
\end{tabular}

${ }^{a} 90 \%$ confidence interval

${ }^{\mathrm{b}}$ Not significant $(\mathrm{n} / \mathrm{s})$

${ }^{c}$ Distance in meters to nearest active nest

${ }^{\mathrm{d}}$ Above ground level

${ }^{\mathrm{e}}$ Distance in meters from nest entrance to indicated feature

${ }^{\mathrm{f}}$ Diameter at breast height

${ }^{\text {aa }}$ Mean vector of entrance orientations

${ }^{\mathrm{bb}}$ Not applicable (n/a)

${ }^{\mathrm{cc}}$ Number with dbh $>10 \mathrm{~cm}$ within $15 \mathrm{~m}$ of nest tree

${ }^{\mathrm{dd}}$ Number within $30 \mathrm{~m}$ of nest tree

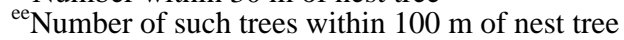


when we compared mean vector for natural nest cavity entrances reported by Snyder et al. (1987) within the same nesting area (i.e., South Fork) with that of used artificial cavities. Moreover, the proportion of downhill-facing natural nest entrances reported by Snyder et al. (1987) was identical (6/7) to this study. Thus, based on observed patterns, Puerto Rican Parrots apparently are selecting against eastward, uphill-facing nest cavities. Nonrandom orientations of nest cavity entrances also have been reported for Hispaniolan Parrots (Amazona ventralis; Snyder et al. 1987), Williamson (Sphyrapicus thyroideus) and Rednaped Sapsuckers (S. nuchalis) (Crockett and Hadow 1975), Common Flickers (Colaptes auratus; Inouye 1975), and several other cavity nesters (Connor 1975, Stauffer and Best 1982, Korol and Hutto 1984, Hardy and Morrison 2001). In those studies, thermoregulatory advantages and protection from inclement weather were most often cited as factors influencing cavity orientations. Because of the geographic location and topographic features of the CNF, prevailing winds and rain blow primarily from a northeasterly direction, and sweep down ridges into adjacent valleys (Snyder et al. 1987, Ostertag et al. 2005). For Puerto Rican Parrots, cavities that provide greater protection from the frequent rain and winds (i.e., westerly, downhill facing) may also have greater adaptive value for successful nesting. In steep, mountainous areas such as the $\mathrm{CNF}$, westerly facing cavities may also provide increased solar exposure during late afternoon before ambient temperatures begin to decline at nightfall, thereby reducing the range of daily temperature fluctuations within nest cavities (McComb and Noble 1981, Hardy and Morrison 2001, Wiebe 2001).

For some avian species, nests located within foodrich habitat patches are more productive than those within areas of sparse resources (e.g., Hussell and Quinney 1987, Finch 1989, Li and Martin 1991); yet for others, nest sites providing greater protection from predators are more adaptive (e.g., Belles-Isles and Picman 1986, Martin and Roper 1988, Wightman and Fuller 2005). However, these factors are not mutually exclusive. Selection by Puerto Rican Parrots for nest sites in patches with greater densities of mature sierra palms likely reflects three mutually compatible adaptive strategies. First, by nesting in areas with higher concentrations of a key food source (e.g., sierra palm), nesting parrots may maximize foraging efficiency and minimize time spent away from the nest, thereby increasing incubation and brooding efficiency. Indeed, Puerto Rican Parrots that are more attentive to incubation and brooding activities are more successful nesters than parrots that spend more time away from the nest (Wilson et al. 1995, 1997). Secondly, by reducing their foraging radius, nesting adults may simultaneously reduce their own exposure to Redtailed Hawk predation, and more effectively foil potential nest predations and usurpations by Pearlyeyed Thrashers (Margarops fuscatus), their primary nest predator and competitor in the CNF (Wiley 1985, Snyder et al. 1987, White et al. 2005a). Finally, once chicks have fledged, adults and fledglings normally remain near $(<100 \mathrm{~m})$ the nest site for several days, until fledglings are capable of more extensive forays (Snyder et al. 1987; T. White, pers. observ.). During this period, close proximity of a variety of foods, such as sierra palm, may constitute a survival advantage for the family group by allowing parrots to forage with minimal movements, potentially reducing predation risk from raptors (Snyder et al. 1987). Although sierra palm fruits tend to be more abundant earlier in the nesting season, ripe palm fruits are nevertheless available during fledging (April-June; Lugo and Frangi 1993, Wunderle 1999, Thompson-Baranello 2000). According to Bannister (1970), a mature sierra palm produces an average of 5000 fruits/year, making even a few fecund palms a potentially important food source. Accordingly, nest sites with greater numbers of such palms may provide an advantage to parrots from a greater abundance and diversity of resources throughout the nesting cycle.

Predator avoidance most likely also explains parrots' selection for nest sites with greater visibility from the nest entrance. Götmark et al.'s (1995) "trade-off hypothesis" of nest site selection stated that, where predation is a major selection pressure and where thermoregulation is of minor importance, nesting birds should benefit from selecting more open nest sites over more concealed sites. Götmark et al. (1995) also listed four potential benefits accrued to nesting birds from good visibility at the nest. Among these, avoidance of predation on adults and watching for nest predators may be the most important benefits for Puerto Rican Parrots. Nest sites with a clear view of the immediate surroundings can provide nesting birds with the opportunity to effectively scan for potential predators and react appropriately (see Belles-Isles and Picman 1986, Finch 1989, Li and Martin 1991). This is particularly true for cavity nesters such as parrots, as they can be highly vulnerable to predators 
when entering and exiting nests (see Gnam and Rockwell 1991, Brightsmith 2005, Stahala 2005). Nesting behavior of Puerto Rican Parrots is characterized by extreme vigilance at and near nest sites, with circumspect nesting birds normally spending several minutes quietly scanning the surroundings before entering or exiting nest cavities. At the slightest disturbance, nesting Puerto Rican Parrots will either quickly retreat back into the nest interior, or immediately vacate the nest vicinity if outside the nest entrance (Snyder et al. 1987, Wilson et al. 1995; T. White, pers. observ.). Similar nesting behavior has been reported in Blackbilled Parrots (Amazona agilis; Koenig 2001), and observed in Hispaniolan Parrots and Bahama Parrots (Amazona leucocephala bahamensis; T. White, pers. observ.). Intuitively, nest sites that facilitate nest vigilance for such species should provide an adaptive advantage in more effective predator detection and avoidance.

Adaptive preferences in nest site selection reflect the influence of species-specific selection pressures (Nilsson 1984, Brightsmith 2005). For the Puerto Rican Parrot, predation on adults and juveniles by Red-tailed Hawks, and nest predation and usurpation by Pearly-eyed Thrashers, have been major factors limiting productivity and population growth in the CNF (Snyder et al. 1987, Wiley et al. 2004). Accordingly, adaptive responses of Puerto Rican Parrots to these factors should result in behaviors, such as nest site selection, designed to maximize individual fitness and, consequently, species persistence (Brightsmith 2005). Not surprisingly, both the current artificial and natural nest sites used in the past by Puerto Rican Parrots share some common characteristics, suggestive of nest site selection influenced by a temporally constant selection pressure. Based on this study and earlier work, we believe predation pressure to be the primary factor influencing nest site selection by Puerto Rican Parrots, which respond by selecting nest sites that provide advantages in predator detection and avoidance at all stages of the nesting cycle. Our findings are consistent with Götmark et al.'s (1995) trade-off hypothesis of nest site selection in explaining current nesting behavior of Puerto Rican Parrots in the CNF.

\section{CONCLUSION}

The recovery plan for the Puerto Rican Parrot includes reestablishment of additional wild populations, the first of which is in the Rio Abajo Commonwealth Forest in north central Puerto Rico (U. S. Fish and Wildlife Service 1999, Wiley et al. 2004, Collazo et al. 2006). Because the Rio Abajo area is, like most of Puerto Rico, predominately secondary forest, natural cavities are currently limited and the provision of artificial nest cavities is recommended to ensure initial availability of suitable nest sites for reintroduced parrots. Given our findings, management strategies for future reintroduced populations in Puerto Rico should consider placement of artificial cavities at sites with similar site-specific functional characteristics as those used by parrots in the CNF. For example, suitable nest sites should facilitate predator detection and avoidance and foraging efficiency for nesting adults, provide maximum protection from inclement weather, and promote fledging success and survival of young. Integrating area-specific information on fruiting phenologies, microclimate, topography, and forest structure would help optimize placement of artificial cavities. In a broader sense, the same model could also be applied to prioritize and select natural cavities for specific enhancements to increase their suitability for parrot nesting (see Snyder et al. 1987, Vilella and Garcia 1995). Because most of the potentially suitable areas for parrot reintroductions in Puerto Rico are currently within government (i.e., USA and Puerto Rico) protected and managed areas (U. S. Fish and Wildlife Service 1999), necessary habitat data are available and accessible to managers (e.g., Trujillo 2005).

For endangered birds, improved nesting success can yield dividends in lower extinction probabilities. Identifying biologically relevant variables that influence nest site selection is an essential step toward developing effective management strategies for such species. In cases where nest site availability limits productivity, efforts to identify and replicate the "nest gestalt" of successful nesting sites may be an effective tool in promoting population growth, and potentially avoiding extinction. 
Responses to this article can be read online at: http://www.ace-eco.org/voll/iss3/art5/responses/

\section{Acknowledgments:}

We thank the U.S. Fish and Wildlife Service and the U.S.D.A. Forest Service for providing funding, access, and logistical support for this study. W. Abreu, G. Benitez, M. Lopez, and M. Toledo generously assisted with data collection. W. Arendt, F. Nuñez-Garcia, S. Koenig, and J. Wunderle provided helpful comments on earlier versions of this manuscript. We thank T. Nudds and two anonymous reviewers for constructive comments that improved the final version. We also are grateful to Élizabeth Powles for the French translation of the abstract.

\section{LITERATURE CITED}

Agresti,A. 1990. Categorical data analysis. Wiley, New York, New York, USA.

Bannister, B. A. 1970. Ecological life cycle of Euterpe globosa Gaertn. Pages B299-B314 in H. T. Odum, editor. A tropical rain forest. Division of Technical Information, United States Atomic Energy Commission, Washington, D.C., USA.

Battin, J., and J. J. Lawler. 2006. Cross-scale correlations and the design and analysis of avian habitat selection studies. Condor 108:59-71.

Belles-Isles, J. C., and J. Picman. 1986. Nesting losses and nest site preferences in House Wrens. Condor 88:483-486.

Brightsmith, D. J. 2005. Competition, predation and nest niche shifts among tropical cavity nesters: phylogeny and natural history evolution of parrots (Psittaformes) and trogons (Trogoniformes). Journal of Avian Biology 36:64-73.

Brown, C. R., M. B. Brown, and E. Danchin. 2000. Breeding habitat selection in Cliff Swallows: the effect of conspecific reproductive success on colony choice. Journal of Animal Ecology 69:133142.

Carey, A. B., T. M. Wilson, C. C. Maguire, and
B. L. Biswell. 1997. Dens of northern flying squirrels in the Pacific Northwest. Journal of Wildlife Management 61:684-699.

Caughley, G. C. 1977. Analysis of vertebrate populations. Wiley, New York, New York, USA.

Chernick, M. R. 1999. Bootstrap methods: a practitioner's guide. Wiley, New York, New York, USA.

Collazo, J. A., M. J. Groom, S. M. Haig, T. H. White, and B. D. Muiznieks. 2006. In the eye of the hurricane: efforts to save the Puerto Rican Parrot. Essay 15.5. Pages 586-589 in M. J. Groom, G. K. Meffe, and C. R. Carroll, editors. Principles of conservation biology, $3^{\text {rd }}$ edition. Sinauer Associates, Sunderland, Massachusetts, USA.

Connor, R. N. 1975. Orientation of entrances to woodpecker nest cavities. Auk 92:371-374.

Crockett, A. B., and H. H. Hadow. 1975. Nest site selection by Williamson and Red-naped Sapsuckers. Condor 77:365-368.

Doligez, B., E. Danchin, J. Clobert, and L. Gustafsson. 1999. The use of conspecific reproductive success for breeding habitat selection in a non-colonial, hole-nesting species, the Collared Flycatcher. Journal of Animal Ecology 68:11931206.

Esely, J. D. Jr., and E. K. Bollinger. 2001. Habitat selection and reproductive success of Loggerhead Shrikes in northwest Missouri: a hierarchical approach. Wilson Bulletin 113:290-296.

Filiater, T. S., R. Breitwisch, and P. M. Nealen. 1994. Predation on Northern Cardinal nests: does choice of nest site matter? Condor 96:761-768.

Finch, D. M. 1989. Relationships of surrounding riparian habitat to nest-box use and reproductive outcome in House Wrens. Condor 91:848-859.

Gnam, R. S., and R. F. Rockwell. 1991. Reproductive potential and output of the Bahama Parrot (Amazona leucocephala bahamensis). Ibis 133:400-405.

Götmark, F., D. Blomqvist, O. C. Hohansson, and J. Bergkvist. 1995. Nest site selection: a trade-off between concealment and view of the surroundings? 
Journal of Avian Biology 26:305-312.

Gutzwiler, K. J., and S. H. Anderson. 1987. Multiscale associations between cavity-nesting birds and features of Wyoming streamside woodlands. Condor 89:534-548.

Hardy, P. C., and M. L. Morrison. 2001. Nest site selection by Elf Owls in the Sonoran Desert. Wilson Bulletin 113:23-32.

Holway, D. A. 1991. Nest-site selection and the importance of nest concealment in the Blackthroated Blue Warbler. Condor 93:575-581.

Hussell, D. J. T., and T. E. Quinney. 1987. Food abundance and clutch size of Tree Swallows Tachycineta bicolor. Ibis 129:243-258.

Inouye, D. W. 1975. Nonrandom orientation of entrance holes to woodpecker nests in aspen trees. Condor 78: 101-102.

Joern, W. T., and J. F. Jackson. 1983. Homogeneity of vegetational cover around the nest and avoidance of nest predation in mockingbirds. Auk 100:497-499.

Johnson, D. H. 1980. The comparison of usage and availability measurements for evaluating resource preference. Ecology 20:553-562.

Koenig, S. E. 2001. The breeding biology of Blackbilled Parrot Amazona agilis and Yellow-billed Parrot A. collaria in Cockpit Country, Jamaica. Bird Conservation International 11:205-225.

Koenig, S. E., J. M. Wunderle, Jr., and E. Enkerlin-Hoeflich. 2007. Vines and canopy contact: a route for snake predation on parrot nests. Bird Conservation International 17: in press.

Korol, J. J., and R. L. Hutto. 1984. Factors affecting nest site location in Gila Woodpeckers. Condor 86:73-78.

Li, P., and T. E. Martin. 1991. Nest-site selection and nesting success of cavity-nesting birds in high elevation forest drainages. Auk 108:405-418.

Lindsey, G. D. 1992. Nest guarding from observation blinds: strategy for improving Puerto Rican Parrot nest success. Journal of Field Ornithology 63:466-472.
Lindsey, G. D., W. J. Arendt, J. Kalina, and G. W. Pendleton. 1991. Home range and movements of juvenile Puerto Rican Parrots. Journal of Wildlife Management 55:318-322.

Loiselle, B. A., and W. G. Hoppes. 1983. Nest predation in insular and mainland lowland rainforest in Panama. Condor 85:93-95.

Lugo, A. E., and J. L. Frangi. 1993. Fruit fall in the Luquillo Experimental Forest, Puerto Rico. Biotropica 25:73-84.

Lumsden, H. G. 1986. Choice of nest boxes by Tree Swallows, Tachycineta bicolor, House Wrens, Troglodytes aedon, Eastern Bluebirds, Sialis sialis, and European Starlings, Sturnus vulgaris. Canadian Field Naturalist 100:343-349.

MacKenzie, D. I., S. G. Sealy, and G. D. Sutherland. 1982. Nest-site characteristics of the avian community in the dune-ridge forest, Delta Marsh, Manitoba: a multivariate analysis. Canadian Journal of Zoology 60:2212-2223.

Martin, T. E. 1992. Breeding productivity considerations: what are the appropriate habitat features for management? Pages 455-473 in J. M. Hagan and D. W. Johnson, editors. Ecology and conservation of neotropical migrants. Smithsonian Institution Press, Washington, D.C., USA.

Martin, T. E. 1993. Nest predation and nest sites: new perspectives on old patterns. Bioscience 43:523-532.

Martin, T. E., and J. J. Roper. 1988. Nest predation and nest-site selection of a western population of the Hermit Thrush. Condor 90:51-57.

McComb, W. C., and R. E. Noble. 1981. Microclimates of nest boxes and natural cavities in bottomland hardwoods. Journal of Wildlife Management 45:284-289.

Munro, H. L., and R. C. Rounds. 1985. Selection of artificial nest sites by five sympatric species. Journal of Wildlife Management 49:264-276.

Nilsson, S. G. 1984. The evolution of nest-site selection among hole-nesting birds: the importance of nest predation and competition. Ornis Scandinavica 15:167-175. 
Nimitz, W. F. 2005. Habitat use and activity patterns of Red-tailed Hawks in occupied and historic Puerto Rican Parrot habitat. Thesis, Mississippi State University, Mississippi State, Mississippi, USA.

Ostertag, R., W. L. Silver, and A. E. Lugo. 2005. Factors affecting mortality and resistance to damage following hurricanes in a subtropical moist forest. Biotropica 37:16-24.

Ricklefs, R. E. 1969. An analysis of nesting mortality in birds. Smithsonian Contributions in Zoology 9:1-48.

Rodriguez-Vidal, J. A. 1959. Puerto Rican Parrot (Amazona vittata vittata) study. Department of Agriculture, Commonwealth of Puerto Rico, Monograph No. 1. Rio Piedras, Puerto Rico.

Roper, J. J. 2003. Nest-sites influence nest predation differently at natural and experimental nests. Ornitologia Neotropical 14:1-14.

Schmidt, K. A., and C. J. Whelan. 1999. Nest placement and mortality: is nest predation a random event in space and time? Condor 101:916-920.

Sedgwick, J. A., and F. L. Knopf. 1990. Habitat relationships and nest site characteristics of cavitynesting birds in cottonwood floodplains. Journal of Wildlife Management 54:112-124.

Sieving, K. E. 1992. Nest predation and differential insular extinction among selected forest birds of central Panama. Ecology 73:2310-2328.

Snyder, N. F. R., J. W. Wiley, and C. B. Kepler. 1987. The parrots of Luquillo: natural history and conservation of the Puerto Rican Parrot. Western Foundation of Vertebrate Zoology, Los Angeles, California, USA.

Sokal, R. R., and F. J. Rohlf. 1981. Biometry. W. H. Freeman and Co., New York, New York, USA.

Stahala, C. 2005. Demography and conservation of the Bahama Parrot on Great Abaco Island. Thesis, North Carolina State University, Raleigh, North Carolina, USA.

Stauffer, D. F., and L. B. Best. 1982. Nest-site selection by cavity-nesting birds of riparian habitats in Iowa. Wilson Bulletin 94:329-337.
Steele, B. B. 1993. Selection of foraging and nesting sites by Black-throated Blue Warblers: their relative influence on habitat choice. Condor 95:568-579.

Switzer, P. V. 1997. Past reproductive success affects future habitat selection. Behavioral Ecology and Sociobiology 6:65-72.

Thompson-Baranello, J. J. 2000. Resource and population modeling of the Puerto Rican Parrot (Amazona vittata). Thesis, University of Puerto Rico, Rio Piedras, Puerto Rico.

Trujillo, A. M. 2005. Evaluation of the suitability of the karst region of north-central Puerto Rico for the reintroduction of the Puerto Rican Parrot (Amazona vittata). Thesis, University of Puerto Rico, Mayagüez, Puerto Rico.

U.S. Fish and Wildlife Service. 1999. Technical/ Agency draft revised recovery plan for the Puerto Rican parrot (Amazona vittata). U.S. Fish and Wildlife Service, Region 4, Atlanta, Georgia, USA.

Vilella, F. J., and E. R. Garcia. 1995. Posthurricane management of the Puerto Rican Parrot. Pages 618-621 in J. A. Bissonette and P. R. Krausman, editors. Proceedings of the First International Wildlife Management Congress. (San Jose, Costa Rica, 1995). The Wildlife Society, Bethesda, Maryland, USA.

Walsberg, G. E. 1981. Nest-site selection and the radiative environment of the Warbling Vireo. Condor 83:86-88.

Weidinger, K. 2002. Interactive effects of concealment, parental behaviour and predators on the survival of open passerine nests. Journal of Animal Ecology 71:424-437.

White, T. H. Jr., W. Abreu-González, M. ToledoGonzález, and P. Torres-Báez. 2005a. From the field: artificial nest cavities for Amazona parrots. Wildlife Society Bulletin 33:756-760.

White, T. H. Jr., J. L. Bowman, H. A. Jacobson, B. D. Leopold, and W. P. Smith. 2001. Forest management and female black bear denning. Journal of Wildlife Management 65:34-40.

White, T. H. Jr., J. A. Collazo, and F. J. Vilella. 2005b. Survival of captive-reared Puerto Rican Parrots released in the Caribbean National Forest. 
Condor 107:424-432.

White, T. H. Jr., and F. J. Vilella. 2004. Nest management for the Puerto Rican Parrot: gaining the technological edge. Ornitologia Neotropical 15 (suppl.):467-476.

Wiebe, K. L. 2001. Microclimate of tree cavity nests: is it important for reproductive success in Northern Flickers? Auk 118:412-421.

Wightman, C. S., and M. R. Fuller. 2005. Spacing and physical habitat selection patterns of Peregrine Falcons in Central West Greenland. Wilson Bulletin 117:226-236.

Wiley, J. W. 1985. The Puerto Rican Parrot and competition for its nest sites. Pages 213-223 in P. J. Moore, editor. Conservation of island birds. ICBP Technical Publication No. 3, Cambridge, UK.

Wiley, J. W., R. S. Gnam, S. E. Koenig, A. Dornelly, X. Galvez, P. E. Bradley, T. White, M. Zamore, P. R. Reillo, and D.Anthony. 2004. Status and conservation of the family Psittacidae in the West Indies. Journal of Caribbean Ornithology (Special Issue) 17:94-154.

Wilson, K. A., R. Field, and M. H. Wilson. 1995. Successful nesting behavior of Puerto Rican Parrots. Wilson Bulletin 107:518-529.

Wilson, K. A., M. H. Wilson, and R. Field. 1997. Behavior of Puerto Rican Parrots during failed nesting attempts. Wilson Bulletin 109:490-503.

Wunderle, J. M. Jr. 1999. Pre- and post-hurricane fruit availability: implications for Puerto Rican Parrots in the Luquillo Mountains. Caribbean Journal of Science 35:249-264. 